\title{
Surgical management of scimitar syndrome: An alternative approach
}

John W. Brown, MDa

Mark Ruzmetov, MDa

Douglas J. Minnich, BS ${ }^{a}$

Palaniswamy Vijay, PhD, MPH

Christopher A. Edwards, BA ${ }^{a}$

Paul N. Uhlig, MD ${ }^{\mathrm{b}}$

Andrew C. Fiore, $M D^{\mathrm{C}}$

Mark W. Turrentine, MD

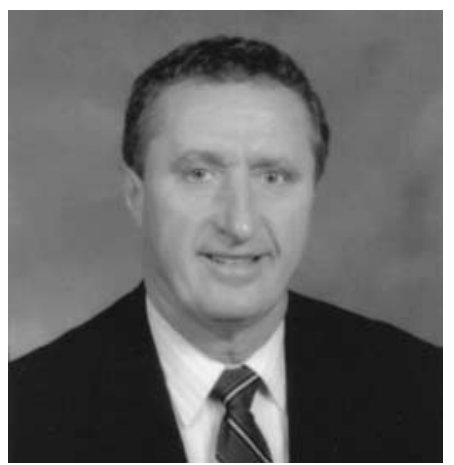

Dr Brown
From the Section of Cardiothoracic Surgery, James W. Riley Hospital for Children and Indiana University School of Medicine, Indianapolis, Ind, ${ }^{a}$ Central Plains Cardiothoracic Surgery, Wichita, Kan, ${ }^{\mathrm{b}}$ and the Section of Cardiothoracic Surgery, Cardinal Glennon Children's Hospital, St Louis University School of Medicine, St Louis, Mo. ${ }^{\mathrm{c}}$

Read at the Eighty-first Annual Meeting of The American Association for Thoracic Surgery, San Diego, Calif, May 6-9, 2001.

Received for publication May 14, 2002; revisions requested May 21, 2002; revisions received June 28, 2002; accepted for publication July 3, 2002.

Address for reprints: John Brown, MD, Section of Cardiothoracic Surgery, Indiana University School of Medicine, 545 Barnhill Dr, EH 215, Indianapolis, IN 462025123 (E-mail: jobrown@iupui.edu).

J Thorac Cardiovasc Surg 2003;125:238-45

Copyright (C) 2003 by The American Association for Thoracic Surgery

0022-5223/2003\$30.00+0

doi:10.1067/mtc.2003.113
Objective: The scimitar syndrome is a congenital anomaly that consists in part of total or partial anomalous venous drainage of the right lung to the inferior vena cava. Surgical approaches to the scimitar syndrome have varied according to the anatomic and pathologic features presented in each case. The aim of this study was to present an alternative approach to the surgical correction of scimitar syndrome.

Methods: Nine patients with the scimitar syndrome were operated on between 1990 and 2000. They comprised 1 male and 8 female patients (mean age $11.5 \pm 17.6$ years). All patients had symptoms, with recurrent pneumonia or respiratory tract infections and pulmonary/systemic flow ratios greater than 1.5:1.0. None of the patients had pulmonary hypertension or an atrial septal defect. All patients underwent repair of the anomalous scimitar vein by direct reimplantation into the left atrium without cardiopulmonary bypass. Two patients underwent concomitant resection of a right lower lobe sequestration. Follow-up was complete in all cases.

Results: There were no operative or late deaths, and no patients have required reoperation. At the time of follow-up (mean $55 \pm 46$ months), echocardiography demonstrated a patent anastomosis in all patients without any evidence of restenosis.

Conclusion: This clinical experience indicates that an alternative surgical approach to scimitar syndrome is direct anastomosis of the scimitar vein to the posterior aspect of the left atrium using a right thoracotomy without cardiopulmonary bypass. This procedure is safe and effective and obviates the need for long intra-atrial baffles and the use of the extracorporeal circuit.

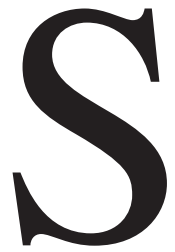

cimitar syndrome (SS) is a rare condition consisting of anomalous pulmonary venous drainage from the right lung to the inferior vena cava (IVC). The extent to which the right lung is drained by the scimitar vein varies from partial to complete. SS has been associated with a number of other abnormalities including hypoplastic right lung, anomalous systemic arterial supply to the right lung with or without pulmonary sequestration, pulmonary hypertension, dextroposition of the heart, and atrial septal defect (ASD, with ostium secundum being the most common). ${ }^{1}$ The term $S S$ derives from the shadow created by the anomalous pulmonary vein on the chest radiograph. This shadow extends from the lateral superior position of the right lung to a more medial location and increases in caliber as it descends toward the cardiophrenic angle. The appearance closely resembles that of a curved Turkish sword or scimitar. ${ }^{2}$

Surgical approaches to SS have varied according to the anatomic and pathologic features presented in each case. The classic operation entails construction of a long 
TABLE 1. Clinical characteristics, treatments used, and outcomes

\begin{tabular}{|c|c|c|c|c|c|c|c|c|c|}
\hline Age & Sex & $\begin{array}{c}\text { Date of } \\
\text { operation } \\
\text { (mo/y) }\end{array}$ & Symptoms & $\begin{array}{l}\text { Associated } \\
\text { defects }\end{array}$ & $\begin{array}{c}\text { PAP (S/D, mm } \\
\mathrm{Hg})\end{array}$ & Qp/0s & $\begin{array}{c}\text { Echocardiogram } \\
(\mathrm{mo} / \mathrm{y})\end{array}$ & $\begin{array}{c}\text { Venous } \\
\text { anastomosis }\end{array}$ & $\begin{array}{c}\text { Follow-up } \\
\text { (mo) }\end{array}$ \\
\hline $7 \mathrm{mo}$ & $\mathrm{F}$ & $7 / 92$ & $\begin{array}{l}\text { Recurrent } \\
\text { pneumonia }\end{array}$ & $\begin{array}{l}\text { Extralobar } \\
\text { sequestration } \\
\text { RLL }\end{array}$ & $36 / 12$ & NA & $1 / 97$ & Patent & 54 \\
\hline 9 y & $\mathrm{F}$ & $10 / 90$ & Cough, dyspnea & None & $35 / 10$ & $1.7: 1.0$ & $3 / 02$ & Patent & 137 \\
\hline $2 y^{*}$ & $\mathrm{~F}$ & $8 / 98$ & $\begin{array}{l}\text { Recurrent } \\
\text { pneumonia }\end{array}$ & $\begin{array}{l}\text { Extralobar } \\
\text { sequestration } \\
\text { RLL }\end{array}$ & $35 / 15$ & $2.0: 1.0$ & $4 / 00$ & Patent & 20 \\
\hline $1.5 y^{*}$ & $\mathrm{~F}$ & $8 / 98$ & $\begin{array}{l}\text { Recurrent } \\
\text { pneumonia }\end{array}$ & None & $25 / 13$ & $1.8: 1.0$ & $12 / 01$ & Patent & 39 \\
\hline $43 \mathrm{y} \dagger$ & $\mathrm{F}$ & 2/93 & URT infection & None & $39 / 10$ & 3.1:1.0 & $4 / 96$ & Patent & 38 \\
\hline 3 y & M & $7 / 88$ & $\begin{array}{l}\text { Recurrent } \\
\text { pneumonia }\end{array}$ & $\begin{array}{l}\text { Extralobar } \\
\text { sequestration } \\
\text { RLL }\end{array}$ & $32 / 6$ & 1.6:1.0 & $7 / 98$ & Patent & 120 \\
\hline $4.5 \mathrm{y}$ & $\mathrm{F}$ & $11 / 95$ & $\begin{array}{l}\text { Recurrent } \\
\text { respiratory } \\
\text { infection }\end{array}$ & None & $28 / 4$ & $1.8: 1.0$ & $3 / 01$ & Patent & 64 \\
\hline 2 y & $\mathrm{F}$ & $12 / 99$ & $\begin{array}{l}\text { Dyspnea, } \\
\text { recurrent } \\
\text { pneumonia }\end{array}$ & $\begin{array}{l}\text { Extralobar } \\
\text { sequestration } \\
\text { RLL }\end{array}$ & $29 / 10$ & $1.6: 1.0$ & $4 / 01$ & Patent & 16 \\
\hline 42 y & $\mathrm{F}$ & $8 / 00$ & $\begin{array}{l}\text { Recurrent } \\
\text { pneumonia }\end{array}$ & None & $18 / 4$ & $2.8: 1.0$ & $2 / 01$ & Patent & 6 \\
\hline
\end{tabular}

$P A P$, Pulmonary artery pressure; $P A P$, pulmonary artery pressure; $S / D$, systolic/diastolic; $Q p / Q s$, pulmonary/systemic flow ratio; $R L L$, right lower lobe; $N A$, not available; URT, upper respiratory tract.

*Patients from St Louis University School of Medicine, St Louis, Missouri.

tPatient from Central Plains Cardiothoracic Surgery, Wichita, Kansas.

intra-atrial baffle from the entry point of the scimitar vein into the inferior vena cava to the left atrium through an ASD. This requires cardiopulmonary bypass with or without deep hypothermic circulatory arrest. This baffle technique has worked well for older patients, but important shortcomings are its inability to address stenoses at the insertion of the scimitar vein into the IVC, potential baffle contracture, and the need for cardiopulmonary bypass with or without circulatory arrest. In this report we describe a simpler technique in which the scimitar vein is anastomosed directly to the left atrium through a right thoracotomy. This procedure addresses any stenosis present at the insertion of the scimitar vein into the IVC, avoids the use of baffles, and obviates the need for the extracorporeal circuit.

\section{Material and Methods}

\section{Patient Data}

We reviewed medical records of all patients with the diagnosis of SS who were cared for at Indiana University School of Medicine, Indianapolis. From 1970 to 2000, a total of 21 patients had SS diagnosed, and 6 of those patients did not have an ASD. These 6 patients, plus 2 patients from St Louis University School of Medicine and 1 patient from Central Plains Cardiothoracic Surgery, Wichita, Kansas, all with SS and intact atrial septum, form the basis of this report. Among the remaining 15 patients, 4 patients did not undergo an operation, because of premature death in the case of 3 neonates and because of the absence of symptoms with low pulmonary shunt ratio in the remaining case. The other 11 patients were operated on with the conventional intra-atrial baffle technique and are excluded from this analysis. The age at presentation, sex, symptoms, associated anomalies, cardiac catheterization data, and outcome were recorded for each patient (Table 1). The patients ranged in age from 7 months to 43 years $(11.5 \pm 17.6$ years). In all cases the entire pulmonary venous drainage from the right lung entered the inferior vena cava below the diaphragm.

Pulmonary sequestration was defined as a segment of the right lower lobe not connected to the tracheal bronchial tree. The systemic arterial supply to the sequestered lobe came from the descending thoracic aorta, with the venous drainage entering the scimitar vein to the inferior vena cava (extralobar sequestration).

The diagnosis of extralobar sequestration was made at the time of thoracotomy or before the operation by chest radiography or computerized axial tomography. The indication for resection of the sequestered lobe was chronic recurrent infections. Follow-up was obtained by parent or patient interview and was complete for all patients at a mean of $55 \pm 46$ months.

\section{Operative Technique}

In each case the patient received general anesthesia endotracheally and was placed in the left lateral decubitus position. A right anterior lateral thoracotomy through the fifth or sixth intercostal 


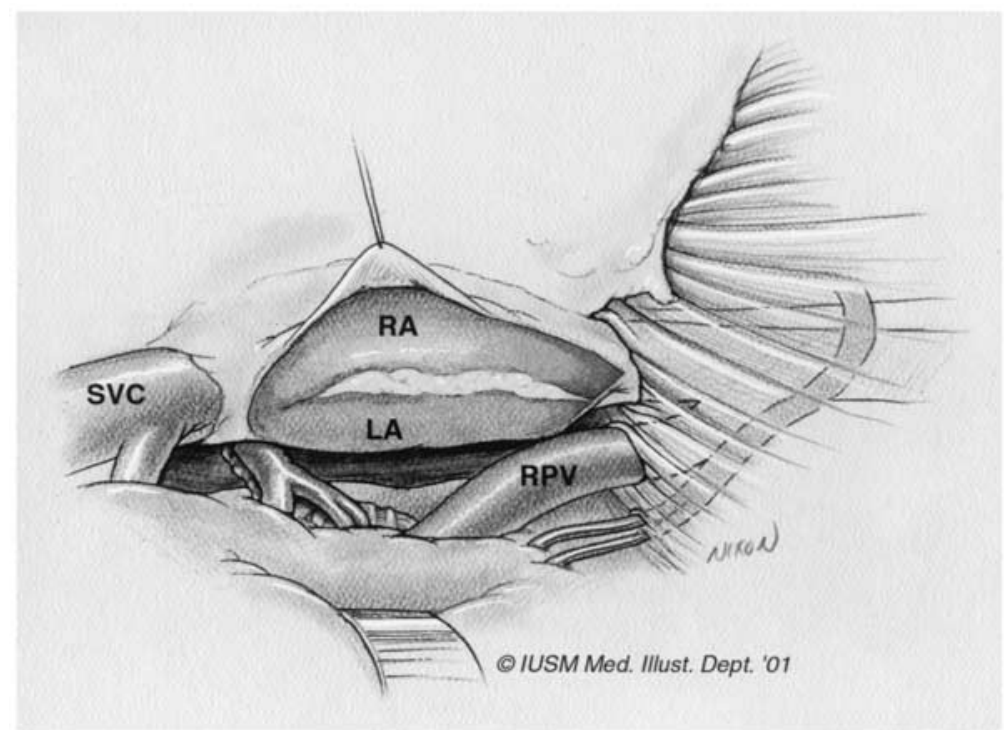

Figure 1. Course of right pulmonary vein (RPV, scimitar vein) as it enters subdiaphragmatic inferior vena cava as viewed from right fifth intercostal space. Note close proximity of scimitar vein to posterior left atrial (LA) wall. RA, Right atrium; $S V C$, superior vena cava.

space was performed. The right lung was freed from all adhesions, and the inferior pulmonary ligament was divided. The inferior draining pulmonary (scimitar) vein was identified and freed from its surrounding tissue to provide greater mobility (Figure 1). In patients with right lower lobe sequestration, the anomalous systemic arteries supplying this sequestered lobe (Table 1) were divided. The diaphragm was opened and the scimitar vein dissected, freeing it as close to its entrance with the inferior vena cava as possible. Opening the pericardium posterior to the phrenic nerve and taking down the pericardial attachments around the inferior vena cava improved exposure at the scimitar vein-IVC entrance. The right pulmonary artery was circumferentially dissected and encircled with a vessel loop. The patients were treated with heparin, and with an activating clotting time in excess of 400 seconds the right pulmonary artery and the scimitar vein were occluded. A cold lap pad was placed posteriorly, and topical ice slush was used to cool the lung. The core body temperature was chilled to $35^{\circ} \mathrm{C}$. A partial occluding clamp was placed on the IVC at the entrance of the scimitar vein, and the vein was divided. The opening in the IVC was oversewn with continuous absorbable monofilament suture. A window of pericardium was removed from the posterior lateral portion of the pericardial sac posterior to the phrenic nerve. The interatrial groove was dissected to expose a generous portion of the left atrium. A partial occluding clamp was applied to the posterior lateral wall of the left atrium. A longitudinal incision was made into the left atrium. The scimitar vein, after mild spatulation of the open end, was anastomosed to the left atrium in end-to-side fashion with continuous 6-0 absorbable monofilament suture (PDS polydioxanone [Ethicon, Inc, Somerville, NJ] or Maxon polyglyconate [United States Surgical Corporation, Norwalk, Conn]; Figure 2). The patient was placed in the Trendelenburg position, and air was removed from the scimitar vein. The left atrial clamp was removed, and air was allowed to escape before removal of the vessel loop on the right pulmonary artery. The pericardium was left open wide enough to avoid herniation, and the thoracotomy incision was closed.

\section{Results}

Nine patients underwent repair of SS by the reimplantation technique. The most common preoperative symptoms were recurrent pneumonia and upper respiratory infections in all patients. Although the interatrial septum was intact in all patients, the pulmonary/systemic flow ratio through the scimitar vein exceeded 1.5:1.0. Pulmonary hypertension was not present in any patient. Pulmonary sequestration was observed in 4 patients (44\%). At the time of scimitar vein repair, resection of a right lower lobe sequestration was performed in 2 patients. Collateral artery supply to the right lower lobe was surgically divided in 4 patients and was coil embolized before the operation in 1 patient.

There were no operative or late deaths. Follow-up was complete for all patients. No patient has required reoperation to date. Echocardiography performed after the operation demonstrated normal low-velocity phasic flow at the venoatrial anastomosis without evidence of stenosis or obstruction in any patient (Figures 3 and 4).

\section{Discussion}

SS is a rare congenital abnormality that occurs in approximately 2 of every 100,000 live births. This is probably an underestimate of the relative frequency, however, because many patients have no symptoms and therefore do not have their disease diagnosed. Patients with SS may be seen in infancy, childhood, or adulthood. 


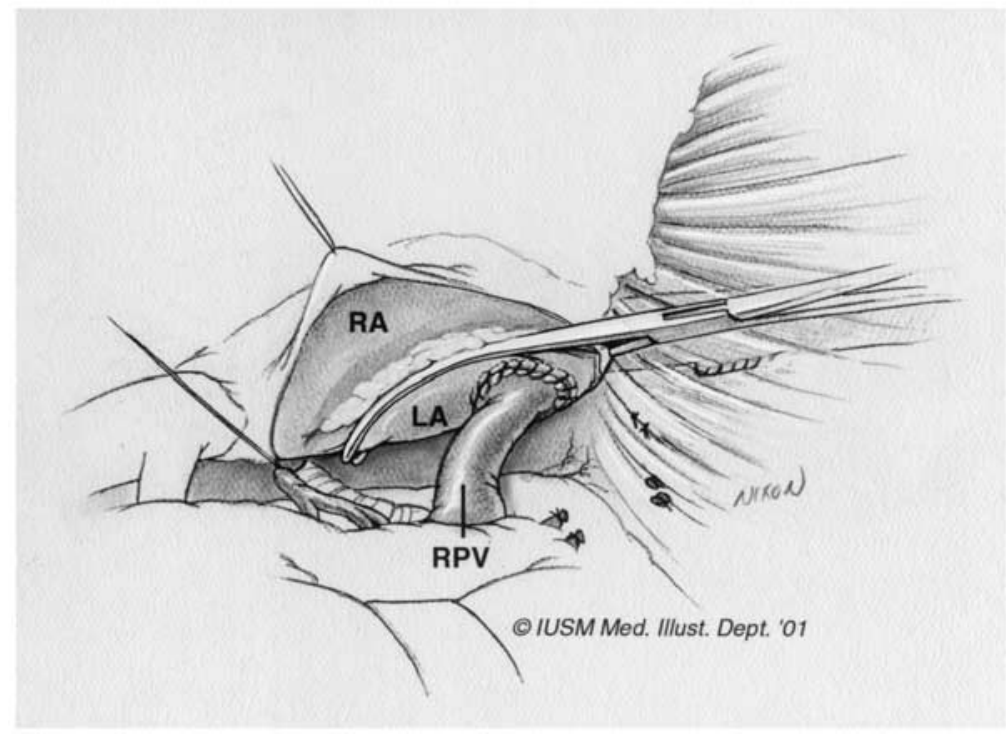

Figure 2. View of right pulmonary vein (RPV, scimitar vein) after detachment from inferior vena cava and reimplantation into posterior inferior wall of left atrium (LA) with side-biting vascular clamp as viewed through right fifth intercostal space. $R A$, Right atrium.

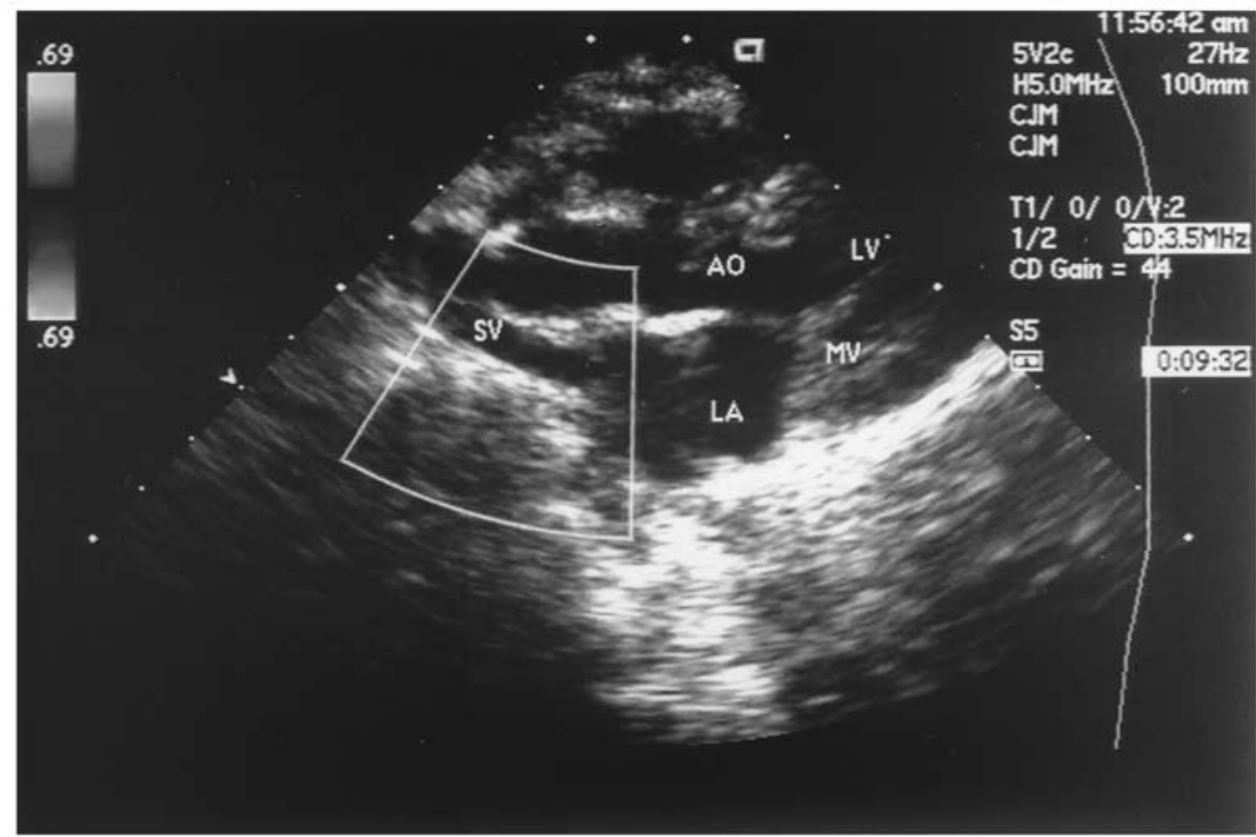

Figure 3. Short-axis transthoracic echocardiographic view demonstrating unobstructed course of anomalous right pulmonary vein (scimitar vein [SV] 2 years after direct reimplantation into left atrium (LA). AO, Aorta; $L V$, left ventricle; $M V$, mitral valve.

Infants typically have features of congestive heart failure from a significant left-to-right shunt from the anomalous pulmonary venous drainage or more commonly from an additional cardiac defect, such as ASD. The scimitar sign is usually absent in infants. ${ }^{3}$ Older children and adults may have symptoms, and the diagnosis may be made from a chest radiograph that demonstrates the scimitar sign in as many as $70 \%$ of patients, because hypoplasia of the right lung is usually absent in this population. If the atrial septum is open $(25 \%-50 \%$ of older patients), examination of the heart may elicit the salient characteristics of an ASD, and the 


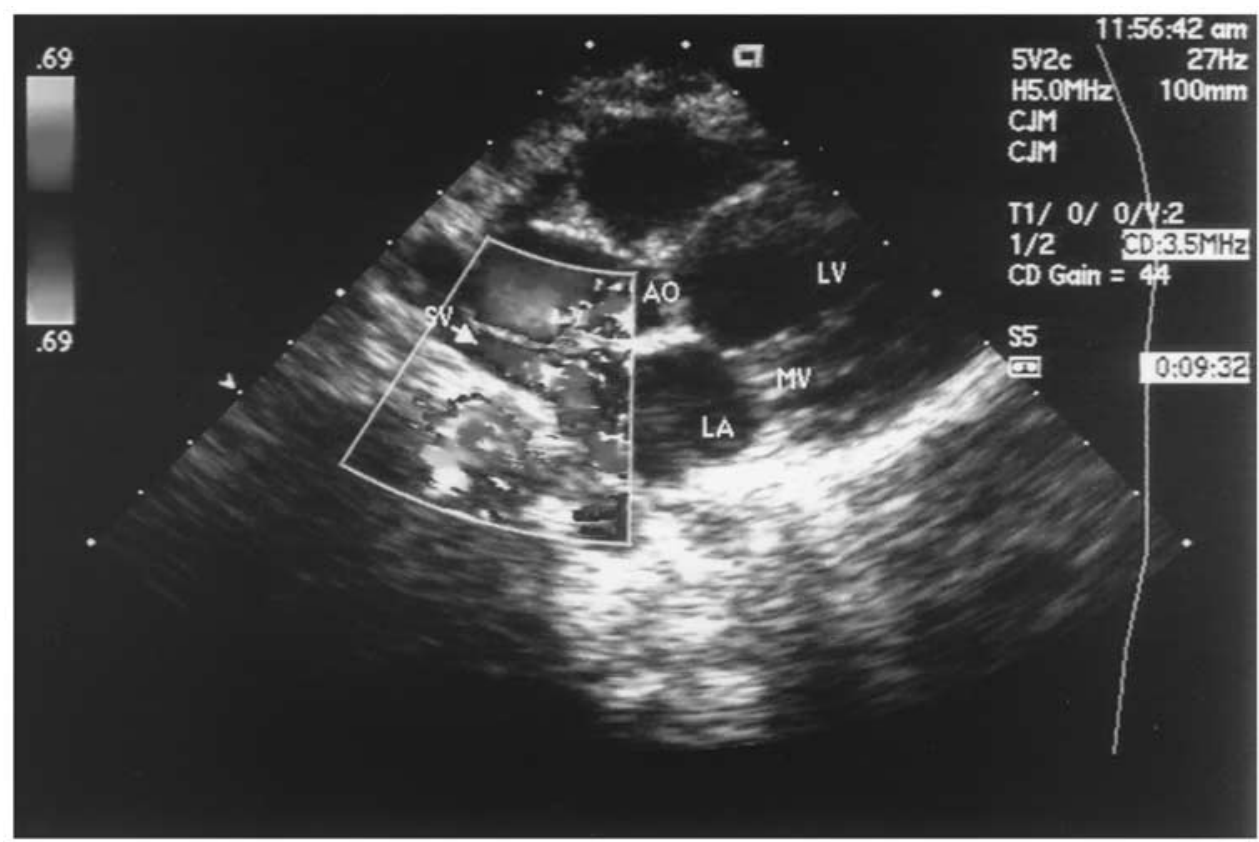

Figure 4. Short-axis transthoracic Doppler echocardiographic view demonstrating widely patent anastomosis of scimitar vein (SV) to left atrium (LA) 2 years after reimplantation. $A 0$, Aorta; $L V$, left ventricle; $M V$, mitral valve.

features of SS will become evident. ${ }^{4}$ In our series of older patients with an intact atrial septum, the symptoms were recurrent pneumonia or upper respiratory tract infections and not congestive heart failure, an observation made by other investigators who have followed up older patients with this disease. ${ }^{5}$

It is important to note that dextroposition of the heart, particularly in association with hypoplasia of the right lung, is a common observation with this syndrome and may be the first clue to the diagnosis. Cardiac catheterization should always be performed to confirm the diagnosis, identify the specific course of the anomalous pulmonary venous drainage, determine the presence of scimitar vein stenosis and pulmonary hypertension, measure the degree of left-to-right shunting, and detect any associated cardiac abnormalities. Pulmonary hypertension is nearly always present in infants but is rare in older children and adults. ${ }^{6}$ None of our patients had elevated pulmonary arterial pressures at the time of scimitar vein transfer.

In some patients with SS, an abnormal systemic artery originating from the thoracoabdominal aorta and coursing through the inferior pulmonary ligament supplies part of the right lower lobe. ${ }^{7}$ This systemic artery can produce a significant left-to-right shunt and potentially contribute to pulmonary hypertension. ${ }^{8}$ Anomalous systemic arterial supply to the right lung should be identified and coil embolized at the time of catheterization or surgically divided at repair. This was successfully accomplished in 4 cases in this series through the right thoracotomy incision. The risk of lung infarction with this procedure has not been reported to date. Two patients underwent resection of the sequestered lobe concomitantly with repair of SS. The reason for the pulmonary resection was chronic pulmonary infections.

The indications for surgical repair include the presence of SS, especially in association with ASD, pulmonary hypertension, or stenosis of the anomalous vein. Scimitar vein stenosis has been noted in $10 \%$ to $20 \%$ of cases and in conjunction with the ASD may cause pulmonary hypertension. ${ }^{9}$ It is important that the surgical procedure chosen correct the stenosis in the scimitar vein; if pulmonary hypertension persists after repair, lung transplantation should be pursued because the long-term mortality among these patients is high.

In neonates and young infants a trial of medical therapy as the initial approach is reasonable to allow an increase in size before repair of the defect. However, the presence of pulmonary hypertension or lack of response to medical therapy demands prompt surgical treatment. Although our youngest patient in this report was 7 months old, we believe that this technique can be applied to infants and neonates should they be deemed candidates for surgical repair at this early age. Our technique is simple and is performed without the need for cardiopulmonary bypass and circulatory arrest, which we feel is a safer approach for infants and neonates. The anastomosis is performed with absorbable suture, which does allow for growth in smaller patients.

The operative approach to correct SS is quite variable. The first report of surgical therapy for SS was in 1950 by Drake and Lynch, ${ }^{10}$ who performed a right lower lobectomy. However, effort should be made to avoid lung resection. Simple ligation of the anomalous pulmonary vein usually results in pulmonary edema, infarction, or both and is not advised. In 1956 Kirklin and associates $^{11}$ reported the first successful physiologic correction by anastomosing the common right pulmonary vein to the right atrial wall, adjacent to an ASD. The atrial wall was then sutured to the margins of the ASD. In 1961 Tornvall and colleagues ${ }^{12}$ reported successful reimplantation of the scimitar vein directly into the left atrium. 
Several methods with cardiopulmonary bypass have been recommended to repair this anomaly, including direct anastomosis of the scimitar vein to the left atrium, as reported by Honey, ${ }^{13}$ or division with reimplantation of the anomalous pulmonary vein into the right atrium with baffle insertion to redirect the flow into the left atrium, as proposed by Shumacker and Judd. ${ }^{14}$ Alternatively, an intra-atrial patch may be used to create a tunnel, redirecting flow from the anomalous pulmonary vein to the left atrium through an ASD, as described by Zubiate and Kay in 1962. ${ }^{15}$ Puig-Massana and Revuelta ${ }^{16}$ described use of the free wall of the right atrium to create a tunnel from the scimitar vein to the left atrium across an ASD. These last two operations require hypothermic circulatory arrest for accurate suturing of the intra-atrial baffle around the orifice of the anomalous vein within the inferior vena cava. Furthermore, potential stenosis in the orifice of the scimitar vein is not addressed, and there is potential for baffle contracture with late pulmonary venous obstruction.

In this report we have described an off-pump technique for patients without associated intracardiac defects adapted from experience with lung transplantation in which these issues are addressed. After detachment of the scimitar vein from the IVC, the orifice is spatulated to relieve any potential stenosis and the defect in the IVC is closed primarily with absorbable suture to encourage growth. Reimplantation of the scimitar vein into the posterior inferior wall of the left atrium can be accomplished without the use of a baffle or the extracorporeal circuit. To date, none of the patients in our series have had stenosis in the IVC or at the scimitar vein reimplantation site.

Occasionally the scimitar vein may originate posterior to the right hilum and then course anteriorly at the level of diaphragm to enter the inferior vena cava. For cases with this anatomic variant, some authors have recommended primary pneumonectomy, reasoning that reimplantation of the scimitar vein into the right atrium and subsequent baffle repair through the ASD cannot be accomplished without vein kinking. ${ }^{17}$ In this situation we believe that the scimitar vein can be mobilized sufficiently for direct reimplantation into the more posteriorly located left atrium. This may avoid the long-term sequelae of pneumonectomy in children, including scoliosis and chronic respiratory insufficiency.

If a patient is seen for operative correction of SS with an ASD, we still advocate reimplantation of the scimitar vein into the left atrium followed by ASD closure at same sitting through the right thoracotomy incision. Closure of secundum ASDs through a right thoracotomy is commonly done by some surgeons for female patients because of improved cosmetic results. Alternatively, these patients could have the ASD closed at a later date through a limited sternal incision.

It is also important to emphasize that although this technique can be successfully applied to a wide range of patients (including infants and adults), as demonstrated in this report, there are patients with SS who may not be appropriate candidates for this therapy. We are particularly concerned with neonates and infants with severe pulmonary hypertension, right lung hypoplasia, and associated cardiac lesions that may not be amenable to any repair. Lung transplantation may be the only acceptable option for this high-risk subgroup of patients.

Although this series is small and follow-up is still relatively short, the results are encouraging. We believe that this approach to
SS is simple, safe, and effective relative to alternative techniques currently used to treat this challenging group of patients.

\section{References}

1. Cooper G. Case of malformation of the thoracic viscera consisting of imperfect development of right lung, and transposition of the heart. Lond Med Gazette. 1836;18:600-1

2. Sanger PW, Taylor FH, Robicsek F. The scimitar syndrome: diagnosis and treatment. Arch Surg. 1963;86:580-7.

3. Canter CE, Martin TC, Spray TL, Weldon CS, Strauss AW. Scimitar syndrome in childhood. Am J Cardiol. 1986:58:652-654

4. Kiely B, Filler J, Stone S, Doyle EF. Syndrome of anomalous venous drainage of the right lung into the inferior vena cava: a review of 67 reported cases and three new cases in children. Am J Cardiol. 1967; 20:102-16.

5. Najm HK, Williams WG, Coles JG, Rebeyka IM, Freedom RM. Scimitar syndrome: twenty years experience and results of repair. J Thorac Cardiovasc Surg. 1996;112:1161-9.

6. Dupuis C, Charaf LA, Breviere GM, Abou P, Remy-Jardin M, Helmius G. The adult form of the scimitar syndrome. Am J Cardiol. 1992;70(4):502-7

7. Alivizatos P, Cheatle T, De Leval M, Stark J. Pulmonary sequestration complicated by anomalies of pulmonary venous return. J Pediatr Surg. 1985;20:76-9.

8. Woody JN, Graham TP Jr, Bradford WD, Sabiston DC Jr, Canent RV Jr. Hypoplastic right lung with systemic blood supply and anomalous pulmonary venous drainage: reversal of pulmonary hypertension with surgical management in infancy. Am Heart J. 1972;83:82-8.

9. Murphy JW, Kerr AR, Kirklin JW. Intracardiac repair for anomalous pulmonary venous connection of right lung to inferior vena cava. Ann Thorac Surg. 1971;11:38-42.

10. Drake EH, Lynch JP. Bronchiectasis associated with anomaly of the right pulmonary vein and right diaphragm: report of a case. $J$ Thorac Surg. 1950;19:433-7.

11. Kirklin JW, Ellis FH, Wood EH. Treatment of anomalous pulmonary venous connections in association with interatrial communications. Surgery. 1956;39:389-98.

12. Tornvall SS, Jackson KH, Alvayay JC, Vargas AC, Koch W, Zarate E. Anomalous drainage of the pulmonary veins into the inferior vena cava. J Thorac Cardiovasc Surg. 1961;42:413-7.

13. Honey M. Anomalous pulmonary venous drainage of right lung to inferior vena cava (scimitar syndrome): clinical spectrum in older patients and role of surgery. Q J Med. 1977;46:463-83.

14. Shumacker HB, Judd D. Partial anomalous pulmonary venous return with reference to drainage into the inferior vena cava and to an intact atrial septum. J Cardiovasc Surg (Torino). 1964;5:271-8.

15. Zubiate P, Kay JH. Surgical correction of anomalous pulmonary venous connection. Ann Surg. 1962;156:234-50.

16. Puig-Massana M, Revuelta JM. A new technique in the correction of partial anomalous pulmonary venous drainage. J Thorac Surg. 1972; 64:108-13.

17. Huddleston CB, Exil V, Canter CE, Mendeloff EN. Scimitar syndrome presenting in infancy. Ann Thorac Surg. 1999;67:154-60.

\section{Discussion}

Dr Thomas L. Spray (Philadelphia, Pa). SS is a congenital anomaly that is seen across an age range all the way from infancy to adulthood, with variable hypoplasia of the right lung, associated congenital anomalies in many patients, and pulmonary hypertension in some infants. Consistent features are the anomalous drainage of most or all of the right lung to the inferior vena cava at the level of the diaphragm and accessory pulmonary blood flow from aortopulmonary collateral arteries that usually arise from the abdominal aorta. In some patients the left-to-right shunt is relatively insignificant because of the hypoplasia of the lung, whereas in others a significant shunt may be present, with hemodynamic 
consequences similar to those of a large ASD. The group that was presented here today is an unusual, selected population with a significant left-to-right shunt in all cases.

Brown and coworkers have demonstrated excellent results in a selected subset of patients in whom no ASD was present and a significant left-to-right shunt was documented. These patients tend to be older than patients who have associated congenital anomalies, with a mean age of 11 years in this report. The various surgical approaches to SS have all had some incidence of late complications, the most significant of which has been stenosis of the scimitar vein at the reimplantation site either in the right atrium or the left atrium, with occasional occlusion or stenosis of the complicated intra-atrial baffles. Thus Brown and coworkers' technique of direct reimplantation into the left atrium, with its excellent intermediate-term results, is an important potential alternative approach if it can be applied to most patients with this syndrome.

Late occlusion of the Scimitar vein is usually associated with the development of hemoptysis, which may occur years after the repair. Thus of fundamental importance for the analysis of the utility of a new technique is careful, ongoing follow-up.

I have the following questions for Dr Brown. First, do you have contraindications to your alternative approach? Does the presence of severe pulmonary hypertension or significant pulmonary hypoplasia mandate the use of open techniques in your experience?

Second, if you do use open techniques with cardiopulmonary bypass, would you do the implantation in a similar fashion but through a sternotomy?

Third, other authors have described anastomosis of the scimitar vein into the left atrium with cardiopulmonary bypass and their incidence of complications does not appear to be significantly different from those with other baffle-type repairs. Could you comment on why you think that the right thoracotomy approach offers such significantly improved results?

Fourth, the follow-up on the patients described was noted to be complete. However, it is unclear when the echocardiograms performed in the follow-up were done. This was not clear either in the presentation or the article, and I hope you would elucidate whether recent echocardiograms have been done in all cases so that follow-up is in fact complete at present. Do all the patients have a recent echocardiogram, magnetic resonance imaging scan, or other study that shows the anatomy of the venous anastomosis, which could suggest whether early stenosis is occurring in some of these patients? I would be particularly interested in the patient who had a bilobectomy and now has only the right upper lobe vein anastomosed to the left atrium. Is this vein also patent and unobstructed? Have you used perfusion scans, either before or after the operation, as a way of following growth of the anastomosis or flow distribution in these hypoplastic lungs?

Finally, even with snaring of the right pulmonary artery, bronchial flow into the pulmonary bed would supply perfusion to the lung during the anastomosis. Do you clamp the pulmonary vein proximally during this anastomosis or rely simply on pulmonary arterial occlusion to prevent flow while you are making the connection?

The excellent results reported by Brown and coworkers in a small series of patients with SS with an innovative technique will certainly stimulate others to apply this approach to patients with similar anatomy. If long-term follow-up continues to show vein patency without development of stenosis, this technique will be an important new addition to the armamentarium of surgeons dealing with this complex spectrum of pulmonary venous anatomies.

Dr Brown. It turns out that we maybe have been lucky at Indianapolis. This is a consecutive series except for 1 patient. There was another adult patient who had SS, but it was misdiagnosed by our adult cardiologist as a secundum ASD. We did not know that the patient had SS until we had her atrium open. Of course, the pleural space had not been opened. She weighed 70 or $80 \mathrm{~kg}$, and we tunneled her scimitar vein to the left atrium through a large ASD.

All the other patients represented our consecutive series. None of them had demonstrable ASDs. The only patient who started out with elevated pulmonary arterial pressures was the one for whom our senior pediatric cardiologist requested that we only ligate the anomalous systemic arteries first. So we ligated them in the neonatal period. That child did have elevated pulmonary arterial pressures. By the time we did the complete repair, as reported here, the patient's pulmonary arterial pressure was down to normal, and so we went ahead and did the direct attachment of the scimitar vein to the left atrium. So we have been lucky in that no patient in our series had severe pulmonary hypertension at the time of the scimitar vein reimplantation.

I do think that the approach through the right thoracotomy will work for most patients with SS. The only exception might be a patient with some anatomic abnormality that you cannot really reach through a right thoracotomy, such as a coarctation. I think that you can actually get to a ductus through a right thoracotomy, even though I do not know that I have actually ever done it.

Cardiopulmonary bypass was not used or needed in our series. Bypass does not hurt, but if you do not need it, why use it? If the patient had an ASD, it would be easy to cannulate the patient and fix the ASD through a right thoracotomy. I see no reason to use cardiopulmonary bypass if you can do the operation safely without it.

Follow-up is complete. These patients have been called back, they have had echocardiograms at the most recent follow-up, and it appears as though this is a durable repair. We were able to make the anastomosis of the scimitar vein to the left atrium twice as large as the diameter of the scimitar vein. So we were able to make a very generous anastomosis when doing the procedure through a right thoracotomy. We have not done magnetic resonance imaging. I do not see any sense in doing magnetic resonance imaging, which is an expensive examination, when the echocardiogram shows patency of the anastomosis without turbulence. We have not routinely used perfusion scans. There is no question that if there is a hypoplastic right lung the perfusion to that right lung may be diminished, but that does not change our indications for the surgical approach. I would not want to do a pneumonectomy on a patient with SS and a hypoplastic right lung. Repeat right bilobectomy would increase the risk of right scimitar vein occlusion, but we have not seen stenosis or occlusion in our 1 patient.

We do clamp the pulmonary vein during the anastomosis to the left atrium. We occlude the pulmonary artery in a heparinized patient, and we do put a bulldog clamp on the proximal end of the scimitar vein while we are doing the anastomosis.

I hope that I have answered most of the questions. 
Dr Carl L. Backer (Chicago, Ill). I think that you may have once again found a relatively simple solution for a difficult problem.

I would comment that this operation is reminiscent of the Baffes operation for transposition of the great arteries, done in the mid $1950 \mathrm{~s}$, anastomosing the right pulmonary veins to the left atrium. And at least anecdotally we were told that some surgeons that tried to imitate the Baffes operation failed to control the pulmonary artery the way that you did and thus the right lung became engorged with blood during the operation. I think that is a key point.

I also think that the right thoracotomy approach is very useful for these patients, because most of them have dextrocardia. In point of fact, it can be very difficult to approach them through a median sternotomy.

I have one question. The group of patients to which Dr Spray alluded, those with whom we have had the most difficulty, are the ones that are seen within the first couple of weeks after birth with severe pulmonary hypertension and a large ASD. Would you still apply this operation for that type of patient?

Dr Brown. Yes, I would. In fact, I tried to talk our senior pediatric cardiologist into letting me do the scimitar vein anastomosis to the left atrium in the neonate, but he was adamant, after reading some reports in the literature, that the mortality was as high as $50 \%$. And so he wanted me to occlude the anomalous systemic arteries first. And I think, of course, that can now be done in the catheterization laboratory, and that might get these patients out of the neonatal period until they were a few months of age or until their veins were bigger, at which time an even more generous anastomosis could be made. I think with absorbable suture and a big anastomosis and reasonable flow through the scimitar vein, the anastomosis is going to stay patent and grow.

\section{JTCVS On-Line Manuscript Submission and Review}

\section{Please visit http://www.editorialmanager.com/jtcvs/}

Effective September 15, 2001, authors and reviewers may submit manuscripts and reviews electronically via Editorial Manager, our new Web-based system with full electronic submission, review, and status update capabilities.

As we move from paper to electronic submissions, the Editorial Office will make proxy submissions of all manuscripts accompanied by a diskette containing the electronic files of the text, tables, and figures. Editors, authors, and reviewers will receive automatic e-mails when significant events occur.

We strongly encourage all authors and reviewers to use Editorial Manager. Although we will continue to accommodate the submission of paper manuscripts for some months, our goal is to be completely electronic within 9 to 12 months.

All individuals currently in our database for whom we have e-mail addresses will receive via e-mail a system-assigned username and password that can be used to log in to the system without prior registration. All those not receiving the e-mail must register the first time they use the system.

As with any broad systemic change, the conversion to the new system will take some time to complete. We ask your patience as we replace our in-office database with the new system. We also encourage you to take advantage of the speed and efficiency that the new system will provide for us all: editor, author, reviewer, and publisher. 